\title{
Neoadjuvant Therapy for Resectable and Borderline Resectable Pancreatic Cancer
}

\author{
Susan Tsai ${ }^{*}$, Kathleen K. Christians ${ }^{1}$, Ben George ${ }^{2}$, Paul Ritch ${ }^{2}$, Kiyoko Oshima ${ }^{3}$, \\ Parag Tolat ${ }^{3}$, Ashley Krepline', Beth A. Erickson ${ }^{4}$, Douglas B. Evans ${ }^{1}$ \\ ${ }^{1}$ Division of Surgical Oncology, Medical College of Wisconsin, Milwaukee, WI, USA \\ ${ }^{2}$ Division of Hematology/Oncology, Medical College of Wisconsin, Milwaukee, WI, USA \\ ${ }^{3}$ Division of Pathology, Medical College of Wisconsin, Milwaukee, WI, USA \\ ${ }^{4}$ Division of Radiation Oncology, Medical College of Wisconsin, Milwaukee, WI, USA \\ Email: "stsai@mcw.edu
}

Received 17 October 2015; accepted 18 January 2016; published 21 January 2016

Copyright (C) 2016 by authors and Scientific Research Publishing Inc.

This work is licensed under the Creative Commons Attribution International License (CC BY).

http://creativecommons.org/licenses/by/4.0/

(c) (i) Open Access

\begin{abstract}
The majority of patients with localized pancreatic cancer (PC) who undergo surgery followed by adjuvant therapy will develop metastatic disease, suggesting that surgery alone is not sufficient for cure and micrometastases are present even when are not clinically detected. As such, the delivery of early systemic therapy may be a rational alternative to a surgery-first approach, in an effort to provide oncologic therapies which are commensurate with the disease stage, and improve surgical selection. This review details the rationale for a neoadjuvant approach to localized PC and provides specific recommendations for both pretreatment staging and treatment sequencing for patients with resectable and borderline resectable PC.
\end{abstract}

\section{Keywords}

Pancreas Cancer, Neoadjuvant Therapy, Review

\section{Introduction}

Pancreatic cancer is likely to become one of our greatest health care challenges as the majority of affected patients do not have an identifiable or modifiable risk factor; they cannot be identified as a high-risk subset and accurate techniques for early diagnosis do not exist. At present, pancreas cancer is the fourth leading cause of adult cancer mortality in the United States with an expected 46, 420 incident cases and 39,590 deaths in 2015 [1]. Similar to the management of most other solid tumors, surgical resection is thought to be necessary for cure.

${ }^{*}$ Corresponding author.

How to cite this paper: Tsai, S., Christians, K.K., George, B., Ritch, P., Oshima, K., Tolat, P., Krepline, A., Erickson, B.A. and Evans, D.B. (2016) Neoadjuvant Therapy for Resectable and Borderline Resectable Pancreatic Cancer. Journal of Cancer Therapy, 7, 24-40. http://dx.doi.org/10.4236/jct.2016.71004 
However, in contrast to many other solid tumors, pancreatic cancer is now recognized as a systemic disease which is metastatic at diagnosis in almost all patients (albeit radiographically occult in many) [2]. Despite this reality, a surgery-first treatment strategy has remained favored by many oncologists and most surgeons because it can be associated with an immediate complete response (even if not durable) and intense multimodality therapy, especially if given in the neoadjuvant setting, is often difficult to deliver. Although a randomized trial comparing neoadjuvant therapy to surgery first for localized pancreatic cancer has not been attempted in the United States, it has been tried in Europe and failed due to poor accrual [3] [4]. It is unlikely that such a trial will be attempted in the future as such visible differences in treatment sequencing make equipoise hard to achieve for physicians and their bias usually is perceived by the attentive patient.

One of the first papers reporting the results of a prospective trial of preoperative (neoadjuvant) chemoradiation (cXRT) for patients with localized pancreatic cancer was published by Evans, Rich and colleagues in 1992 [5]. This trial evolved from the following clinical observations: (1) a subset of patients who underwent pancreaticoduodenectomy (PD) first experienced early postoperative disease recurrence. Such patients, if treated with a neoadjuvant approach, may be identified at the time of post-treatment re-staging prior to surgery, and thereby be spared the morbidity and mortality of an ineffective operation, (2) neoadjuvant cXRT may be more effective than adjuvant cXRT and may prevent/decrease both local and regional (peritoneal cavity) recurrences and (3) the delivery of adjuvant therapy after a large operation (such as PD) was difficult, and often was not given/completed. In the future, as systemic therapies improve, a surgery-first approach will prevent many patients from receiving effective systemic therapies. When this trial was developed over two decades ago, the hope was that a neoadjuvant treatment strategy would avoid operation in those patients with aggressive tumor biology for whom surgery would be ineffective, and as well, allow us the opportunity to develop the infrastructure needed to deliver more intensive combined modality therapy, including techniques for pretreatment biopsy, biliary decompression, and supportive care. Figure 1 is a contemporary consecutive series of patients from our institution treated with neoadjuvant therapy for resectable or borderline resectable pancreatic cancer. Those patients found to have disease progression at the time of post-treatment/preoperative re-staging (or at the time of laparoscopy/laparotomy) did not undergo resection (Figure 1, curve B); those with stable or responding disease after induction therapy completed all intended therapy, including successful surgical resection of their primary pancreatic tumor (Figure 1, curve A). In the 1990s, when we began to explore novel treatment sequencing in a neoadjuvant fashion, we were focused on preventing surgery in those who were destined to develop early disease progression. Many of the chal-

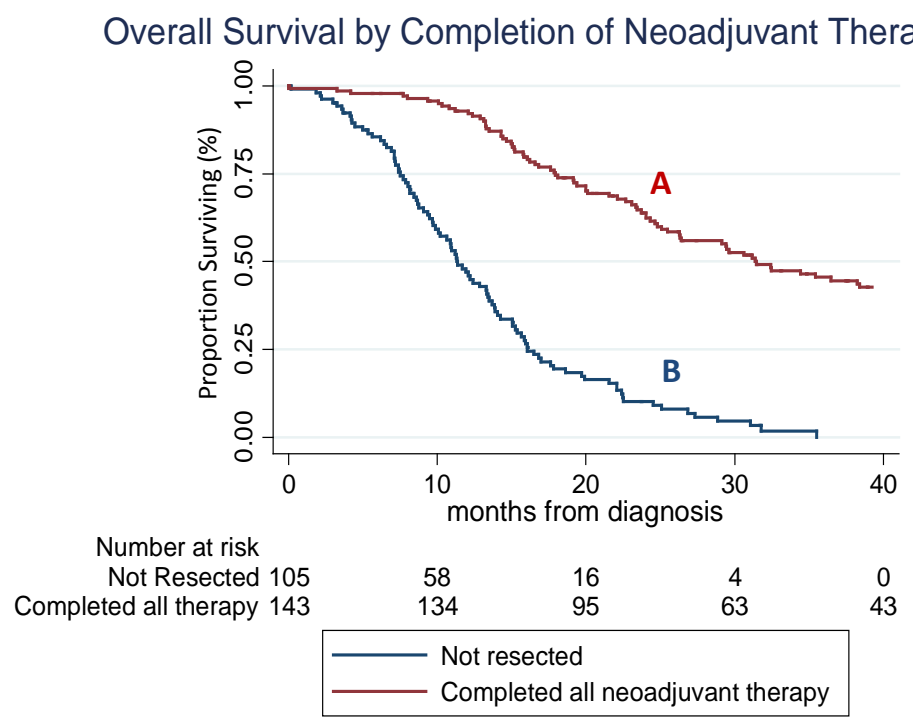

Figure 1. Survival curves for 248 consecutive patients who received neoadjuvant therapy with surgical intent for either resectable or borderline resectable pancreatic cancer from 2009 to 2015. Curve A represents those who did not complete all intended therapy due to disease progression (predominantly in distant sites) or a decline in performance status. Curve B represents those who completed all intended therapy to include potentially curative surgery. Median survival from the time of diagnosis for those who completed all intended therapy to include surgery was 32 months compared to 11 months for those found to have disease progression. 
lenges associated with neoadjuvant therapy for pancreatic cancer (pretreatment tissue acquisition/bio-psy, biliary stenting, delivery of patient-centered multimodality care) are solved and attention is now focused on the favorable survival achieved by those patients who complete all intended multimodality therapy. [6] Such a prolonged survival as seen in Figure 1 (curve A) has not previously been associated with pancreatic cancer, and to the extent that some of this improvement is due to treatment sequencing alone, there appears to be renewed interest in neoadjuvant therapy.

The median survival for patients with pancreatic cancer treated with a surgery-first strategy has not changed over the last three decades [7]. The inadequacy of surgical therapy alone and the inability to reliably deliver adjuvant therapy has led to a more widespread interest in neoadjuvant therapy to improve the length and quality of survival for all treated patients. Neoadjuvant treatment sequencing identifies those patients with rapidly progressive disease, unresponsive to treatment, as distinct from those who receive clinical benefit from induction therapy. While the initial enthusiasm for neoadjuvant therapy was largely focused on preventing surgery in those with rapidly progressive disease, the current enthusiasm is a result of the encouraging survival duration of those who respond (Figure 1, curve A); what characterizes this patient subset that allows for such a robust anti-tumor response? Is systemic therapy more effective on micrometastases in an immune competent host prior to the immune suppression induced by a large operation? These and other questions/controversies of treatment sequencing will be reviewed and specific recommendations for both pretreatment staging and treatment sequencing will be outlined for patients with resectable and borderline resectable pancreatic cancer.

\section{Importance of Pretreatment Staging}

Accurate pretreatment staging is essential for all solid tumor patients, but is particularly important in the management of pancreatic cancer. Pretreatment evaluations should be based on objective and reproducible anatomic definitions to avoid misclassification and incorrect treatment sequencing [8]. Strict adherence to these criteria should be applied not only at initial staging but at serial evaluations to accurately assess treatment efficacy. Multidetector CT provides the most objective data regarding the relationship of the pancreatic tumor to surrounding vascular structures, including the superior mesenteric vein-portal vein (SMV-PV) confluence, superior mesenteric artery (SMA), and the hepatic and celiac arteries. Several groups have described clinical staging criteria for resectable and borderline resectable pancreatic cancer; the criteria used by the authors to define the clinical staging of pancreatic cancer are summarized in Table 1 with representative CT images (Figures 2-4).

Table 1. Medical College of Wisconsin CT-based clinical staging of pancreatic cancer.

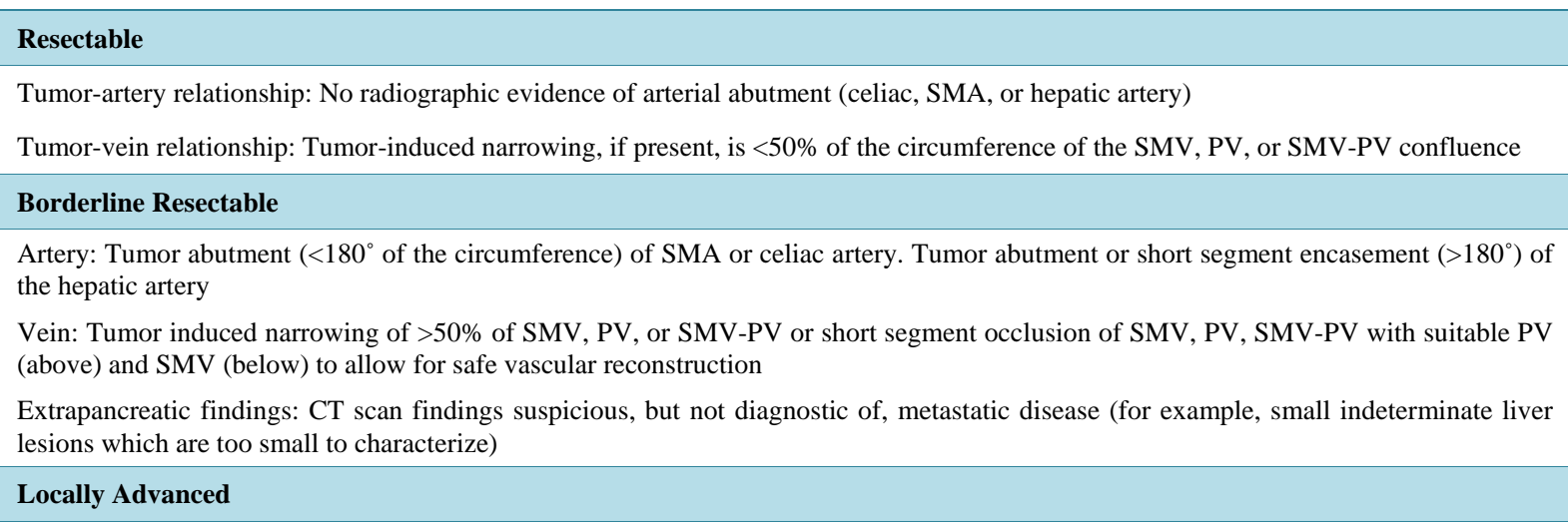

Artery: Tumor encasement ( $>180^{\circ}$ of the circumference) of SMA or celiac artery

Vein: Occlusion of SMV, PV, or SMV-PV without suitable vessels above and below the tumor to allow for reconstruction (no distal or proximal target for vascular reconstruction)

Extrapancreatic findings: No evidence of peritoneal, hepatic, extra-abdominal metastases

Metastatic

Evidence of peritoneal or distant metastases

Abbreviations: SMA, superior mesenteric artery; SMV, superior mesenteric vein; PV, portal vein; SMV-PV, superior mesenteric-portal vein confluence. 


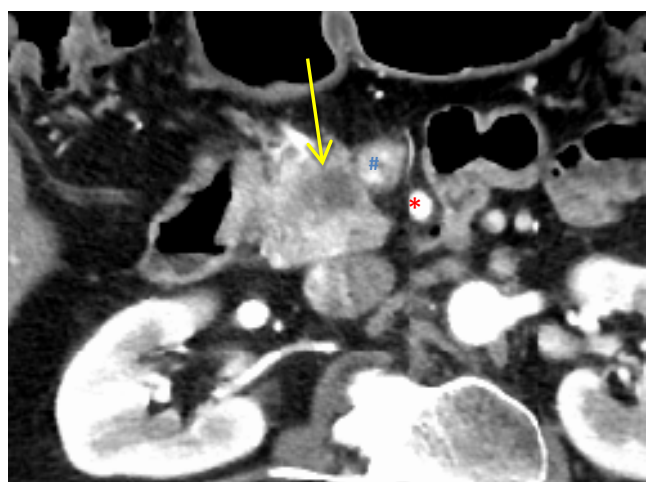

(a)

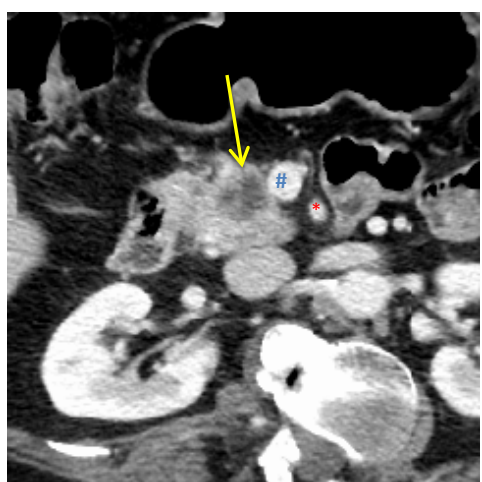

(b)

Figure 2. Axial CT images in the late arterial (Figure 2(a)) and portal-venous (Figure 2(b)) phases of a resectable pancreatic head adenocarcinoma (low-attenuation mass, yellow arrow). Note the tumor remains confined to the pancreas and is distant from the SMA (red *) and does not abut or narrow the SMV (blue \#).

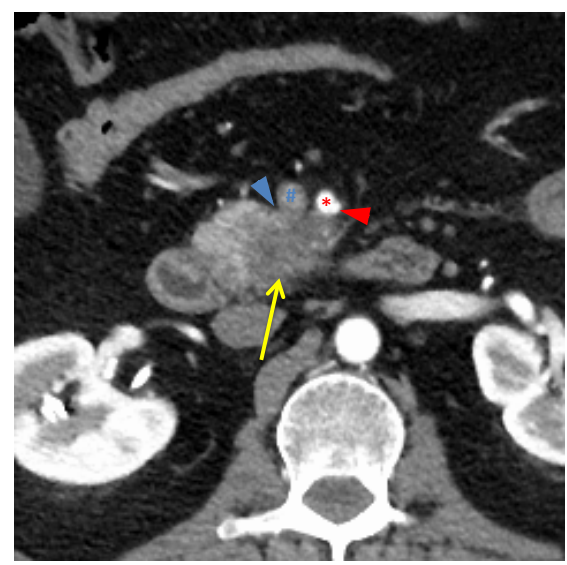

(a)

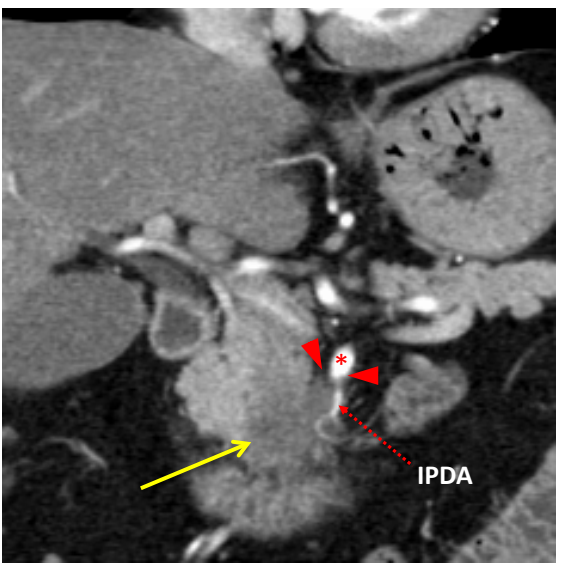

(c)

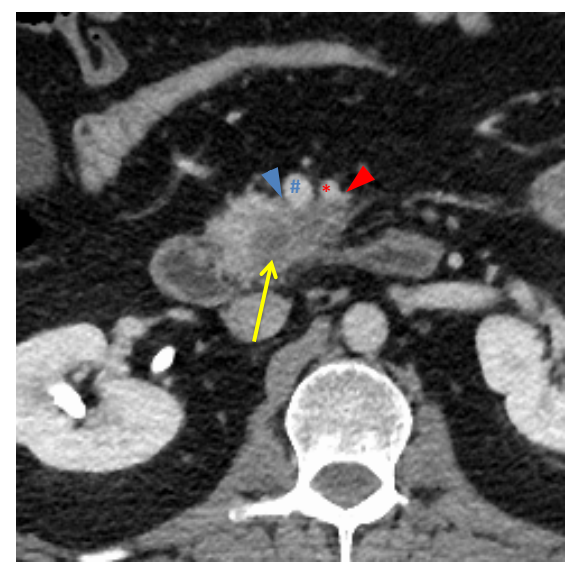

(b)

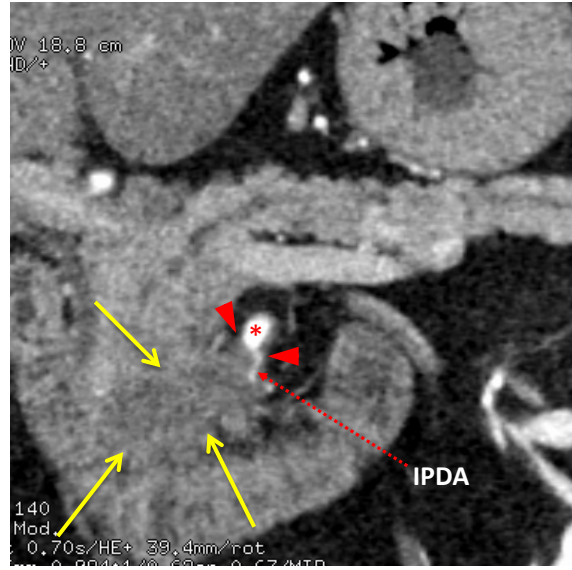

(d)

Figure 3. Axial late arterial (Figure 3(a)), portal venous (Figure 3(b)), coronal arterial (Figure 3(c)), and curved planar venous (Figure 3(d)) phase CT images of a borderline resectable adenocarcinoma (low attenuation mass) of the pancreatic head/uncinate process (yellow arrow). The tumor abuts (arrowheads) the SMA (red *) and SMV (blue \#). Note the low-attenuation soft-tissue that abuts the SMA (including inferior pancreaticduodenal artery (IPDA) branch) and SMV for $180^{\circ}$ or less and obliterates the expected normal fat plane. 


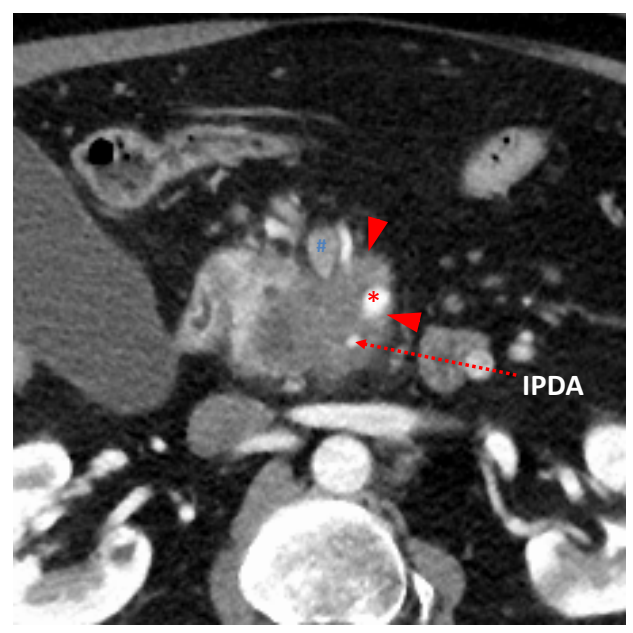

(a)

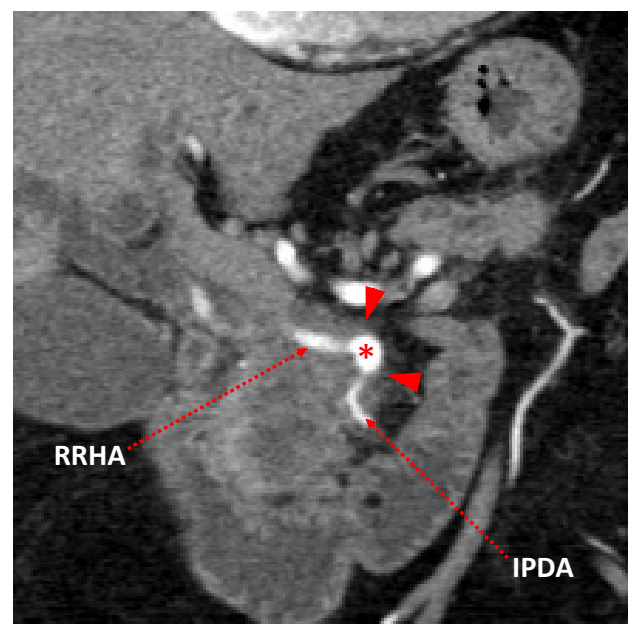

(b)

Figure 4. Axial (Figure 4(a)) and coronal (Figure 4(b)) CT images in the late arterial phase of a locally advanced pancreatic adenocarcinoma of the uncinate process with tumor encasement of the SMA (arrowheads). Note the low-attenuation soft-tissue which encases the SMA (red *), IPDA, and the replaced right hepatic artery (RRHA) for greater than $180^{\circ}$ and the greater than $50 \%$ "tear-drop" shaped narrowing of the SMV (blue \#).

\section{Lessons Learned from Adjuvant Therapy}

Historically, patients managed with surgical resection alone had high rates of local and distant relapse, with local recurrence rates following complete surgical resection reported to be as high as $86 \%$ [9]-[12]. As a result, several prospective randomized trials were initiated to assess the potential benefit of adjuvant chemotherapy or cXRT in improving local disease control and patient survival. The trials, trial designs, and results are listed in Table 2 and provide a benchmark to which neoadjuvant studies must be compared. However, it is important to acknowledge the selection bias inherent in all adjuvant trials; enrolled patients survived surgery and in general, experienced an uncomplicated recovery to allow for trial enrollment. Those patients who experienced a perioperative mortality or delayed recovery were not included, and the number or percentage of those not included is unknown.

Adjuvant cXRT was adopted as standard in the United States shortly after the publication of the Gastrointestinal Tumor Study Group (GITSG) trial in 1985 [13]. In this prospective randomized trial for patients with resected pancreatic cancer, median survival was 20 months for those who received cXRT versus 11 months in the observationarm (surgery alone) despite what is now considered suboptimal cXRT $(p=0.04)$ [13]. Two other prospective randomized controlled trials failed to replicate the results of the GITSG trial; the EORTC trial utilized a similar split course regimen of cXRT as was used in the GITSG trial but provided no additional systemic therapy [9] [14], and the ESPAC1 trial utilized a $2 \times 2$ factorial design to evaluate adjuvant chemotherapy and cXRT [15]. Both trials have been heavily criticized for lack of standardized pathologic evaluation and radiation quality control, low compliance to prescribed therapy, and the absence of rigorous patient monitoring and follow-up. Nevertheless, these trials have changed clinical practice; cXRT is no longer routinely given to post-surgical patients, especially in Europe.

While controversy persists regarding adjuvant cXRT, the reports of several trials support the benefit of adjuvant chemotherapy. The CONKO-001 trial examined the value of adjuvant gemcitabine after pancreatectomy compared to surgery alone [16]. The median overall survival was statistically different between the two armsin favor of gemcitabine therapy ( 22.8 vs. $20.2 \mathrm{mo}, p=0.01$ ); survival rates at 5 -and 10 -years were $20.7 \%$ and $12.2 \%$ in the gemcitabine arm and $10.4 \%$ and $7.7 \%$ in the observation arm. The ESPAC-3 trial compared 6 months of adjuvant bolus 5-FU/folinic acid versus gemcitabine in patients with resected pancreatic adenocarcinoma [17]. Thistrial demonstrated no difference in overall or progression free survival between treatment arms but did demonstrate the importance of completing all planned therapy, even if adjuvant therapy was started greater than eight weeks after surgery [18]. Finally, the Radiation Therapy Oncology Group (RTOG) 9704 trial compared adjuvant systemic gemcitabine versus continuous infusion (CI) 5-FU when given before and after CI 5-FU- 
Table 2. Prospective randomized controlled trials of adjuvant therapy for pancreatic cancer.

\begin{tabular}{|c|c|c|c|c|c|c|}
\hline \multirow[b]{2}{*}{ Study, Year } & \multirow[b]{2}{*}{ Pt No. } & \multicolumn{3}{|c|}{ Was It Standardized? } & \multirow[b]{2}{*}{ Chemotherapy } & \multirow[b]{2}{*}{ Outcome } \\
\hline & & $\begin{array}{l}\text { Pathology } \\
\text { Review }\end{array}$ & $\begin{array}{l}{ }^{*} \text { Pre-Rx } \\
\text { Imaging }\end{array}$ & $\begin{array}{c}\text { Radiation } \\
\text { QA/QC }\end{array}$ & & \\
\hline GITSG [13], 1985 & 43 & No & No & No & Bolus 5-FU & $\begin{array}{l}\text { Improved median survival } \\
\text { for those who received } \\
\text { adjuvant therapy ( } 20 \text { vs. } 11 \\
\text { mo). } 2 \text { yr OS } 42 \text { vs. } 15 \%\end{array}$ \\
\hline EORTC [14], 1999 & 114 & Yes & No & No & 5-FU infusion & $\begin{array}{c}\text { No statistically significant } \\
\text { difference in survival (17.1 } \\
\text { vs. } 12.5 \text { mo) }\end{array}$ \\
\hline ESPAC1 [15], 2004 & 541 & No & No & No & Bolus 5-FU & $\begin{array}{l}\text { Improved median survival } \\
\text { for chemotherapy alone } \\
(19.4 \text { mo). No benefit for } \\
\text { radiation }\end{array}$ \\
\hline $\begin{array}{c}\text { RTOG } 9704 \text { [19], } \\
2006\end{array}$ & 442 & Yes & Yes & Yes & $\begin{array}{l}\text { Gemcitabine vs. } \\
\text { 5-FU infusion }\end{array}$ & $\begin{array}{l}\text { Nonsignificant trend } \\
\text { favoring gemcitabine } \\
\text { before and after } \\
\text { chemoXRT }\end{array}$ \\
\hline $\begin{array}{c}\text { CONKO-001 [16] } \\
\text { [58], } 2007\end{array}$ & 354 & No & No & N/A & Gemcitabine & $\begin{array}{l}\text { Improved median disease } \\
\text { free survival } \\
(13.4 \text { vs. } 6.9 \mathrm{mo})\end{array}$ \\
\hline ESPAC3 [17], 2010 & 1088 & No & No & N/A & $\begin{array}{l}\text { Bolus 5-FU vs. } \\
\text { Gemcitabine }\end{array}$ & $\begin{array}{c}\text { No difference in DFS or } \\
\text { OS between 5-FU and } \\
\text { gemcitabine }\end{array}$ \\
\hline
\end{tabular}

*Before the start of adjuvant therapy (after surgery) to exclude early disease recurrence.

based cXRT [19]. Importantly, a surgery-only “control arm” was not included, a strong indication of the evolving consensus in the United States for the added value of adjuvant systemic therapy. This important paradigm shift serves as a foundation on which neoadjuvant treatment sequencing is based; if we agree that systemic therapy is critically important, it cannot be reliably delivered after PD. Importantly, the trial did not utilize objective radiographic criteria to determine preoperative clinical stage and did not routinely document the surgeon's assessment of whether or not a complete gross resection of the tumor was accomplished. An update of this phase III trial reported in 2011 demonstrated a non-significant trend favoring systemic gemcitabine over CI 5-FU when given before and after 5-FU-based cXRT for pancreatic head adenocarcinomas (median survival 20.5 mo vs. $17.1,5-y r$ OS $22 \%$ vs. $18 \%, p=0.07$ ) [20].

The lack of rigorous clinical and pathologic staging in most adjuvant trials made it very difficult to determine the efficacy of adjuvant cXRT, but has stimulated increased attention to study design, treatment quality control and monitoring, and patient follow up. At present, there is consensus that the incorporation of adjuvant chemotherapy is beneficial and this has been espoused by expert consensus panels as well as the National Comprehensive Cancer Network Practice Guidelines [21]-[24]. Independent of trial design, a significant proportion (a minimum of $30 \%-45 \%$ ) of patients fail to receive intended adjuvant treatment due to lengthy post-operative recovery [25]. For this reason, investigators have hypothesized that moving adjuvant therapy to the preoperative setting will allow all patients to receive systemic therapy. By initiating chemotherapy earlier in the treatment paradigm, systemic treatment will be delivered for a systemic disease, rather than waiting until the patient recovers from a local procedure of significant magnitude during which time radiographically occult distant metastases may progress.

\section{Advantages and Disadvantages of Neoadjuvant Treatment Sequencing}

Neoadjuvant therapy for pancreatic cancer has several theoretical advantages and disadvantages which are summarized in Table 3. Because adjuvant systemic therapy has been demonstrated to prolong survival, utilizing a neoadjuvant paradigm provides an opportunity to ensure the delivery of all components of multimodality treat 
Table 3. Potential advantages and disadvantages of neoadjuvant chemoradiotherapy.

Benefits of Neoadjuvant Therapy
The ability to deliver systemic therapy to all patients: critically important as systemic therapies become more effective and
tumor/patient profiling allow for individualized, personalized medicine
Following neoadjuvant therapy, post-treatment preoperative staging allows for the identification of patients with aggressive tumor
biology, who manifest with disease progression and are unresponsive to available therapies. These patients are spared the toxicity
of surgery
Increased efficacy of radiation therapy if it is incorporated into the treatment program; free radical production in a well oxygenated
environment
Decreased radiation induced toxicity to adjacent normal tissue as the radiated field is resected at the time of pancreatectomy
Decreased rate of positive resection margins; SMA margin in particular
Decreased rate of pancreatic fistula formation
Potential for the downstaging of borderline resectable tumors to facilitate surgical resection
Disadvantages of Neoadjuvant Therapy
Potential for complications from pre-treatment endoscopic procedures; endoscopic ultrasound-guided fine-needle aspiration biopsy and
endoscopic stent placement
Biliary stent occlusion which may occur during neoadjuvant therapy
Disease progression obviating resectability; loss of a “window” of resectability which rarely occurs in the borderline resectable
patient Physicians have to work together during the preoperative phase; discrete handoff from surgeon to medical oncologist to radiation
oncologist, as occurs with adjuvant therapy, is not possible in the neoadjuvant setting
As employees of health systems, surgeons may be incentivized to operate frequently in an effort to meet defined productivity (work
RVU) requirements which impact compensation

ment to all patients who undergo a potentially curative pancreatectomy. In addition, since neoadjuvant therapy offers an "induction" phase lasting approximately 2 - 3 months, individuals with unfavorable tumor biology who develop early metastatic disease are identified prior to surgery. This subset of patients $(10 \%-30 \%)$ isspared the morbidity of an operation and may receive appropriate therapy for distant disease without delay. If cXRT is considered, it is likely more effective at generating free-radicals in a well-oxygenated environment which has not been devascularized by surgical intervention [5] [26]. In addition, the administration of preoperative radiation has been associated with decreased toxicity to adjacent normal tissue and may reduce the risk of peritoneal tumor seeding during the surgical procedure [15]. From a surgical perspective, neoadjuvant chemoradiotherapy may decrease the high rate (up to 50\%) of positive margins (R1 or R2) seen after surgery alone and also reduce the risk of pancreatic fistula formation as the treated pancreas becomes more firm with a decrease in enzyme production [27]-[29].

There are limitations/challenges of neoadjuvant treatment sequencing which havenegatively influenced its more widespread application. A tissue diagnosis is required prior to treatment; currently, this is accomplished using endoscopic ultrasound-guided fine-needle aspiration and available expertise is not consistent across institutions. In addition, patients with tumors in the head of the pancreas frequently require treatment of biliary obstruction with endobiliary stenting. Stent-related morbidities, including cholangitis due to stent occlusion during neoadjuvant therapy, occurs in up to $15 \%$ of patients and requires prompt recognition. [30] However, the use of metal endobiliary stents rather than polyethylene (plastic) stents has reduced stent-related complications [31].

\section{Neoadjuvant Therapy for Resectable Pancreatic Cancer}

A number of single institution studies have reported the use of neoadjuvant cXRT in resectable and borderline resectable pancreatic cancer (Table 4). There port by Evans, Rich and colleagues was the first touse CT-based anatomic definitions for pretreatment and preoperative clinical staging, a standardized surgical technique, and a defined system for pathologic evaluation of the surgical specimen [5]. Given the modest response rates to 5-FUbased chemotherapeutic regimens in unresectable or metastatic pancreatic cancer, investigators then explored alternative systemic therapies, still combined with radiation; radiation was felt to be an important part of the local-regional treatment in combination with surgical excision of the pancreatic tumor. The efficacy of gemcitabine in the treatment of advanced pancreatic cancer, as well as the drug's potent radiosensitizing effect, suggested that it would be an ideal candidate for neoadjuvant study. Building on previous trials using hypofractionation, Evans and colleagues studied 86 patients who received weekly gemcitabine $\left(400 \mathrm{mg} / \mathrm{m}^{2}\right)$ and $30 \mathrm{~Gy}$ of 
Table 4. Selected neoadjuvant trials for resectable and borderline resectable pancreatic cancer.

\begin{tabular}{|c|c|c|c|c|c|c|}
\hline Author, Year & $\begin{array}{l}\text { Clinical } \\
\text { Stage }\end{array}$ & $\begin{array}{l}\text { No. of } \\
\text { Patients }\end{array}$ & Chemo Rx & Radiation & $\begin{array}{l}\text { No. Patients } \\
\text { Resected } \\
(\%)\end{array}$ & $\begin{array}{l}\text { Median Surviv- } \\
\text { al of Resected } \\
\text { Patients (mo) }\end{array}$ \\
\hline Evans [5], 1992 & $\mathrm{R}$ & 28 & 5-FU & $50.4 \mathrm{~Gy} / \mathrm{S}$ & $17(61)$ & 18 \\
\hline Yeung [59], 1993 & $\mathrm{R}$ & 26 & 5-FU, MMC & $50.4 \mathrm{~Gy} / \mathrm{S}$ & $12(46)$ & OS: 8 \\
\hline $\begin{array}{c}\text { Pisters [60], } \\
1998\end{array}$ & $\mathrm{R}$ & 35 & 5-FU & $\begin{array}{c}30 \mathrm{~Gy} / \mathrm{H} \\
\text { Or } 50.4 \mathrm{~Gy} / \mathrm{S}\end{array}$ & $20(57)$ & 25 \\
\hline Hoffman [61], 1998 & $\mathrm{R}$ & 53 & 5-FU, MMC & 50 Gy/S & $24(45)$ & 15.7 \\
\hline White [62], 2001 & $\mathrm{R}$ & 96 & 5-FU & $40 \mathrm{~Gy} / \mathrm{S}$ & $53(55)$ & 23 \\
\hline Pisters [63], 2002 & $\mathrm{R}$ & 37 & paclitaxel & $\begin{array}{l}30 \mathrm{~Gy} / \mathrm{H}, \\
\text { IORT }\end{array}$ & $20(54)$ & 19 \\
\hline Moutardier [64], 2004 & $\mathrm{R}$ & 61 & 5-FU, cisplatin & $30 \mathrm{~Gy} / \mathrm{SC}$ or S & $40(66)$ & 26.6 \\
\hline Mournex [65], 2005 & $\mathrm{R}$ & 41 & 5-FU, cisplatin & $50.4 \mathrm{~Gy} / \mathrm{S}$ & $26(63)$ & $12 / 5$ \\
\hline Talamonti [33], 2006 & $\mathrm{R}$ & 20 & gemcitabine & $30 \mathrm{~Gy} / \mathrm{H}$ & $17(85)$ & 26 \\
\hline $\begin{array}{l}\text { Varadhachary [32], } \\
2008\end{array}$ & $\mathrm{R}$ & 90 & gemcitabine cisplatin & $30 \mathrm{~Gy} / \mathrm{H}$ & $52(58)$ & 31 \\
\hline Evans [32], 2008 & $\mathrm{R}$ & 86 & gemcitabine & $30 \mathrm{~Gy} / \mathrm{H}$ & $64(74)$ & 34 \\
\hline Turrini [66], 2009 & R/BLR & 102 & 5-FU and cisplatin & $45 \mathrm{~Gy}$ & $62(61)^{\dagger}$ & 23 \\
\hline Le Scodan [67], 2009 & $\mathrm{R}$ & 41 & 5-FU, cisplatin & 50 Gy & $26(63)$ & 11.7 \\
\hline Turrini [68], 2010 & $\mathrm{R}$ & 34 & docetaxel & 45 Gy & $15(44)$ & 32 \\
\hline Stokes [52], 2011 & BLR & 40 & capecitabine & 50 Gy & $16(40)$ & 12 \\
\hline Kang [69], 2011 & BLR & 32 & No & $45 / 50.4$ Gy & $23(72)$ & 26.3 \\
\hline Artinyan [70], 2011 & $\mathrm{R}$ & 39 & not available & not available & unknown & 33.8 \\
\hline Lee [71], 2012 & BLR $^{*}$ & 18 & gemcitabine & No & 17 & $23.1^{\dagger}$ \\
\hline Sho [72], 2012 & $\begin{array}{c}\mathrm{R} \\
\mathrm{BLR}\end{array}$ & $\begin{array}{l}22 \\
39\end{array}$ & gemcitabine & $50 / 50.4$ Gy & 59 (97) & $28^{\dagger}$ \\
\hline Pipas [73], 2012 & $\begin{array}{c}\mathrm{R} \\
\mathrm{BLR}\end{array}$ & $\begin{array}{c}4 \\
23\end{array}$ & gemcitabine and cetuximab & 54 Gy & $\begin{array}{l}4(100) \\
18(78)\end{array}$ & $24.3^{\dagger}$ \\
\hline Arvold [74], 2012 & BLR $^{*}$ & 24 & $\begin{array}{l}\text { 5-FU orcapecitabine or } \\
\text { gemcitabine }\end{array}$ & $\begin{array}{l}50.4 \text { Gy or } \\
\text { CRT alone }\end{array}$ & $8(30)$ & NR \\
\hline Barugola [75], 2012 & BLR $^{*}$ & 27 & $\begin{array}{l}\text { gemcitabine, gemcitabine and } \\
\text { cisplatin, or capecitabine }\end{array}$ & $\begin{array}{l}50.6 \mathrm{~Gy} \\
45 \mathrm{~Gy}\end{array}$ & NR & $35^{\dagger}$ \\
\hline Leone [76], 2013 & $\mathrm{BR}^{*}$ & 15 & gemcitabine and oxaliplatin & 50.4 Gy & $9(60)$ & $32^{\dagger}$ \\
\hline Kim [35], 2013 & $\begin{array}{c}\mathrm{R} \\
\mathrm{BR}^{*}\end{array}$ & $\begin{array}{l}23 \\
39\end{array}$ & gemcitabine and oxaliplatin & 30 Gy & $\begin{array}{l}13(56) \\
24(62)\end{array}$ & $27.1^{\dagger}$ \\
\hline Van Buren [77], 2013 & $\begin{array}{c}\mathrm{R} \\
\mathrm{BR}\end{array}$ & $\begin{array}{l}29 \\
29\end{array}$ & gemcitabine and bevacizumab & 30 Gy & $43(74)$ & 19.7 \\
\hline Motoi [78], 2013 & $\begin{array}{c}\mathrm{R} \\
\mathrm{BR}\end{array}$ & $\begin{array}{l}19 \\
16\end{array}$ & gemcitabine or S-1 & None & $30(85)$ & 34.7 \\
\hline Cho [79], 2013 & $\mathrm{BR}$ & 30 & $\begin{array}{l}\text { gemcitabine, }+/- \text { cisplatin } \\
\text { or capecitabine }\end{array}$ & $\begin{array}{l}\text { 45/50.4/58.4 } \\
\text { Gy }\end{array}$ & NR & 45 \\
\hline Rose [37], 2014 & $\mathrm{BR}$ & 64 & gemcitabine, docetaxel & 50.4 Gy & $31(48)$ & $\begin{array}{l}\text { not reached at } \\
21.6 \text { months }\end{array}$ \\
\hline O’Reilly [36], 2014 & $\mathrm{R}$ & 38 & gemcitabine and oxaliplatin & No & $27(71)$ & NR \\
\hline Golcher [4], 2014 & $\mathrm{R}$ & 33 & gemcitabine and cisplatin & 50.4 Gy & $19(58)$ & 25 \\
\hline Epelboym [80], 2014 & BLR $^{*}$ & 134 & various chemotherapy & not available & $114(80)$ & $27.3^{\dagger}$ \\
\hline Blazer [81], 2014 & BRPC & 18 & various regimens & 30/36 Gy & $11(61)$ & NR \\
\hline Christians [6], 2015 & $\mathrm{R}$ & 69 & majority rec'd gemcitabine & 50.4 Gy & $60(87)$ & 45 \\
\hline Katz [82], 2015 & BLR & 22 & FOLFIRINOX & 50.4 Gy & $15(68)$ & NR \\
\hline
\end{tabular}

Abbreviations: 5-FU, 5-Fluorouracil; MMC, mitomycin C; S, standard fractionation; H, hypofractionation; IORT, intraoperative radiation therapy; SC, split course fractionation; NR, not reported "Study includes both BLR and locally advanced PC—only BLR sample size is reported. ${ }^{\dagger}$ Median survival of all; CI, continuous infusion; CT, computed tomography; cXRT, chemoradiation; FNA, fine needle aspirate; FOLFIRINOX, 5-FU, irinotecan, and oxaliplatin; GTX, gemcitabine, docetaxel, capecitabine; PC, Pancreatic cancer; PD, Pancreaticoduodenectomy; PV, Portal Vein; R1, Microscopically positive margin; R2, macroscopically positive margin; SMA, superior mesenteric artery; SMV, superior mesenteric vein. 
radiation [32]. All patients successfully received the prescribed neoadjuvant therapy with dose reductions of gemcitabine required in approximately 50\% of patients. PD was performed in 64 (74\%) patients; median overall survival for the entire cohort and the resected patients was 23 and 34 months respectively. At a minimum follow-up of 5 years for all living patients, 36\% of resected patients were alive; no patient survived who did not complete all therapy to include PD. The median survival of 34 months in the 64 resected patients, a number not previously seen in this disease, was the first signal that treatment sequencing may offer a survival advantage beyond that of patient selection. A gemcitabine-based regimen was also studied in a multi-institutional report of 20 patients with resectable (14) and borderline resectable (6) pancreatic cancer [33]. In this trial, full-dose gemcitabine $\left(1000 \mathrm{mg} / \mathrm{m}^{2}\right)$ was administered with 36 Gyof radiation [33]. Successful pancreatic resection was performed in 17 (85\%) of the 20 patients; median survival was 26 months. Results of initial studies utilizing systemic gemcitabine combined with radiation were encouraging yet distant recurrence remained common, especially in the liver; more robust systemic coverage was clearly needed.

Varadhachary and colleagues incorporated systemic therapy with gemcitabine and cisplatin for 2 months, followed by gemcitabine-based hypofractionated cXRT [32]. Ninety patients were enrolled and 79 (87\%) completed neoadjuvant therapy. Although the trial required a longer preoperative interval to complete chemotherapy followed by cXRT, local tumor progression was not seen and this trial added to other prospective data suggesting that neoadjuvant therapy of reasonable duration does not risk losing a "window of opportunity" for surgical resection of the primary pancreatic cancer. Median survival for all patients was 18.7 months and 31 months for those who completed all therapy to include successful resection of the pancreatic primary. However, results were not improved over the authors' experience with gemcitabine-based cXRT alone, without the induction phase of chemotherapy; but, there was a statistically significant increase in patients with node positive disease in this trial compared to the gemcitabine-based cXRT trial, strongly suggesting a higher proportion of patients with node positive disease (aggressive biology) at trial entry.

Tzeng et al. recently reported a series of 167 patients with resectable pancreatic cancer who received either chemotherapy and/or cXRT followed by resection or resection first, followed by adjuvant therapy [34]. Those patients who completed all multimodality therapy had a median survival over three times as long as those who did not (36 versus 11 months; $p<0.001$ ). The rate of completion of multimodality therapy was $83 \%$ for those being treated with neoadjuvant therapy and only $58 \%$ for those treated in the adjuvant setting. In addition, the patients treated with neoadjuvant therapy had a lower rate of early disease progression and were impacted less severely by postoperative complications. This study underscores the necessity of multimodality therapy for optimal overall survival duration and the superiority of neoadjuvant treatment sequencing in insuring the completion of all therapy. Recent experiences from Memorial Sloan Kettering Cancer Center, the Massachusetts General Hospital, Virginia Mason Medical Center, and the University of Michigan demonstrate the growing enthusiasm for neoadjuvant treatment sequencing and acknowledgement that a surgery-first strategy offers little hope for significant improvements in patient survival [35]-[38].

In summary, the experience with neoadjuvant therapy for patients with resectable pancreatic cancer has demonstrated a survival benefit for those who complete intended therapy and undergo successful resection of the primary tumor as compared to patients treated with a surgery-first strategy who receive postoperative adjuvant therapy. The median survival for patients who undergo PD after successfully completing neoadjuvant systemic gemcitabine and radiation is approaching 3 years - compared to approximately two years (24 months) for those who complete adjuvant therapy after a surgery-first approach, and approximately 12 months for those who fail to receive adjuvant therapy after PD [9] [25] [39]. As a more contemporary example, we recently reported 69 patients who were not eligible for clinical trial enrollment at our institution, and received neoadjuvant therapy for resectable pancreatic cancer. Median survival of all 69 patients was 31.5 months, including 44.9 months for the 60 patients who completed all intended neoadjuvant therapy and successful surgery, as compared to 8.1 months for the 9 patients who did not undergo successful surgery due to disease progression or a decline in performance status [40]. This survival advantage is likely explained by factors other than simply patient selection, including the impact oftreatment sequencing on the host-tumor relationship and treatment response [41]. For example, neoadjuvant therapy provides early treatment of low volume, radiographically occult micrometastases (in liver or lung for example) in the setting of an immune-competent host prior to the stress of a large operation. In addition, these micrometastases, which are present in most patients, may be more vulnerable to systemic therapy when small and radiographically occult. The ability of neoadjuvant therapy to downstage regional lymph node metastases is well described and to the extent that occult liver or lung metastases behave in a similar biologic way, sequencing may matter. Importantly, those patients who evidence disease progression after neo- 
adjuvant therapy are spared a major operation; an operation which, in retrospect, would have resulted in early disease recurrence if a surgery-first treatment approach had been used. Such patients benefit greatly from their accurate identification as a subset having accelerated tumor growth not responsive to a local therapy such as surgery.

\section{Current and Future Neoadjuvant Treatment Schemas for Resectable Disease}

Outside of a clinical trial, the preferred neoadjuvant treatment schema is based on the report of Evans and colleagueswhich applied weekly gemcitabine with radiation [32]. This program resulted in a median survival of almost 3 years in those patients who completed all therapy to include surgery. We have modified this regimen slightly to include a standard fractionation course of cXRT (1.8 Gy/day, M-F, 28 fractions) to a total dose of 50.4 Gy. Gemcitabine is typically given on day 1 (day -2 to +1 ) at a dose of $400 \mathrm{mg} / \mathrm{m}^{2} / \mathrm{week}$ at fixed dose rate over 40 minutes. Restaging with pancreatic protocol CT imaging is completed 4 weeks after the last radiation treatment and in the absence of disease progression, patients are then brought to surgery. The recent reports of both FOLFIRINOX (5-fluorouracil, oxaliplatin, irinotecan, and leucovorin) and gemcitabine/nab-paclitaxel, which demonstrated efficacy in patients with advanced disease, [42] [43] have generated enthusiasm for their use in patients with localized disease, especially those with borderline resectable disease [38] [44] [45]. Current clinical trials are evaluating the use of FOLFIRINOX (5-fluorouracil, oxaliplatin, irinotecan, and leucovorin) and gemcitabine/nab-paclitaxel given prior to surgery (NCT02241551) [46]. Becausec XRT remains controversial, it is likely that physicians in many major medical centers are using neoadjuvant FOLFIRINOX (four cycles) or neoadjuvant gemcitabine/nab-paclitaxel (two cycles), both delivered over approximately 2 months. At the authors' institution, clinical trial development for patients with resectable pancreatic cancer has emphasized molecular profiling of the fine-needle aspiration (FNA) specimen as a guide to the choice of systemic therapy given prior to operation (NCT01726582) [47]. At the time of surgery, we begin each operation with a diagnostic laparoscopy in an effort to avoid laparotomy in those patients with radiographically occult liver or peritoneal metastases. Approximately 5\% - 10\% of patients will have radiographically occult metastatic disease at the time of laparoscopy. Local tumor resectability should be thoroughly assessed by preoperative imaging, and therefore, it should be very rare to abort a planned PD due to local tumor anatomy.

Future neoadjuvant treatment schemas will likely incorporate molecular profiling of the tumor in an effort to tailor the choice of systemic therapy to the potential vulnerabilities of the tumor. As this technologyis incorporated into clinical trials, the debate over the potential added benefit of cXRT will continue. However, as systemic therapies become more effective and median survivals increase, the importance of local disease control may become even more compelling. The biology of treatment response is a complicated process; a complete response in the liver or lung may not be duplicated at the site of the surgical resection bed, where recurrent disease is most often found in the perineural tissues adjacent/surrounding the SMA or celiac artery. Such local disease recurrence (when it occurs) is often complicated by occlusion or significant narrowing of the SMV or SMV-PV confluence which may result in the development of ascites and/or gastrointestinal hemorrhage due to extrahepatic portal hypertension. The importance of local disease control, especially in patients with potentially resectable disease, cannot be overstated-as clinically significant local-regional disease recurrence may be preventable with an optimal operation and the consistent delivery of multimodality therapy to include cXRT either before or after surgery. We may be entering a new era in the management of localized pancreatic cancer where small but clinically significant advances in systemic therapies improve control of distant metastases and patient survivals - to the extent that more patients survive long enough to experience challenging symptoms of local-regional disease recurrence/progression for which we have little contemporary experience.

\section{Neoadjuvant Therapy for Borderline Resectable Cancers}

The median survival of patients with borderline resectable pancreatic cancer who receive multimodality therapy and no surgery is $10-12$ months. A recent meta-analysis examined the resection rates and outcomes in patients who received neoadjuvant therapy, dividing the published literature into those studies reporting patients with resectable or unresectable (including borderline resectable) disease [48]. In this analysis, $42 \%$ of patients initially deemed borderline/unresectable were considered for surgery after neoadjuvant therapy. Of those, $70 \%$ underwent successful pancreatectomy and the rate of R0 resections was observed to be comparable to those patients initially deemed resectable ( $79.2 \%$ vs. $80.2 \%$, respectively). Among the patients with borderline/locally 
advanced tumors who underwent resection, overall survival was prolonged to 20.5 months. The interpretation of these findings is obscured by the lack of uniform definitions of resectability, as it should be very uncommon that a patient with locally advanced disease (when defined as arterial encasement or complete occlusion of the SMVPV) is considered for operation. Nevertheless, although assessment of outcomes in borderline resectable patientsis confounded by this lack of objective, reproducible pretreatment staging, small published series have suggested promising outcomes after neoadjuvant treatment sequencing in this high-risk patient subset. A limited number of studies have exclusively examined the borderline resectable population using more refined criteria/definitions (Table 4).

The largest borderline resectable series is from Katz and colleagues and included 160 patients [49]. Borderline resectable patients were retrospectively categorized into three distinct groups: Group A included patients with CT evidence of arterial abutment, Group B patients had findings suggestive but not diagnostic of metastatic disease, and Group C patients demonstrated a marginal performance status which was felt to be recoverable. The most common treatment sequence was 2 to 4 months of systemic therapy followed by cXRT (30 or 50.4 Gy with either gemcitabine or capecitabine/5-FU) with restaging evaluations every 2 months. Seventy-nine (49\%) of the 160 patients underwent an operation; 66 (41\%) were successfully resected and R0 resections were achieved in 62 (94\%) of 66 patients. The median survival was 40 months for the $41 \%$ of patients who completed all therapy including surgery, and 13 months for those patients who did not complete all intended therapy due to disease progression or evolving/persistent comorbidities. The 5-year survival was 36\% among those who completed all therapy.

A series from H. Lee Moffitt Cancer Center also utilized a paradigm of induction chemotherapy followed by cXRT [50]. In this series, 18 patients with borderline resectable disease received the GTX regimen (gemcitabine, docetaxel, and capecitabine) followed by cXRT. Seventeen (94\%) patients completed neoadjuvant therapy, 14 (82\%) underwent surgery, and 9 (50\%) of the 18patients were successfully resected (R0 resection in 8). Median survival of all 18 patients was 15.6 months and median survival had not been reached among those patients who completed all therapy to include pancreatectomy. The University of Cincinnati reported a retrospective institutional series of 29 patients with borderline resectable disease treated with a variety of different regimens including cXRT alone, chemotherapy alone, and cXRT followed by chemotherapy [51]. Twenty-six (89\%) of the 29 patients completed neoadjuvant therapy; disease progression during/after neoadjuvant therapy occurred in 14 (48\%) of the 29 patients and 12 (41\%) of the remaining 16 patients underwent successful surgery. Median survival for unresected and resected patients was 15.5 months and 23.3 months respectively. Investigators at the University of Virginia also reported aseries of 40 patients with borderline resectable disease treated with 50.4 Gystandard-or 50 Gy accelerated-fractionation cXRT [52]. Thirty-four (85\%) of the 40 patients completed neoadjuvant therapy and 16 patients (40\%) underwent resection; median survival for patients who completed all therapy including surgery was 23 months. Current clinical trials are comparing the efficacy of FOLFIRINOX (5-fluorouracil, oxaliplatin, irinotecan, and leucovorin) versus gemcitabine/nab-paclitaxel given prior to surgery. (NCT02562716).

These promising early results from several small series suggest that the treatment of patients with borderline resectable pancreatic cancer with an organized multimodality neoadjuvant approach results in a survival benefit among patients who are able to complete all intended therapy. In addition, this survival benefit is similar to that seen with patients considered to have resectable pancreatic cancer at the time of diagnosis. Although initial systemic therapy will not benefit all patients with borderline resectable disease, it will identify the cohort of patients who are likely to benefit from surgery — such patients experience clinical benefit, radiographic evidence of stable or responding disease, and often a reduction in serum levels of CA 19 - 9 and/or CEA. Further investigations are needed to determine optimal treatment sequencing and the most effective cytotoxic agents (gemcitabine doublets vs. GTX vs. FOLFIRINOX).

\section{Current Neoadjuvant Treatment Schemas for Borderline Resectable Disease}

With respect to treatment sequencing, patients with borderline resectable pancreatic cancer are fundamentally different from those with resectable disease in that they are: (1) at higher risk for harboring radiographically occult distant metastatic disease; (2) at the highest possible risk for a positive margin of resection due to tumor-artery abutment; (3) require a more complex operation usually involving vascular resection and reconstruction; and therefore; (4) there is a greater possibility that, despite the best efforts of the physician team, a surgical procedure may yield no oncologic benefit for the patient. For these reasons, investigators have applied a more 
robust level of selection consisting of a longer period of induction therapy, often including chemotherapy followed by cXRT. The cXRT portion of induction therapy has been thought to be particularly important for those patients with arterial abutment in the hope of sterilizing at least the periphery of the tumor and thereby preventing a positive margin of resection.

Outside of a clinical trial, the preferred neoadjuvant treatment schema for patients with borderline resectable pancreatic cancer consists of an initial two months of systemic therapy followed by restaging. The choice of systemic agents for the patient's initial treatment has evolved from gemcitabine-based therapies to consideration of FOLFIRINOX, GTX, the recently described gemcitabine doublet including nab-paclitaxel, and others [35] [43] [45] [53]-[55]. Restaging at 2 months intervals should include three critically important criteria: the presence or absence of clinical benefit (e.g., the resolution of pain), CT findings to suggest stable or responding disease vs. disease progression, and the decrease or increase in serum CA 19 - 9 levels [56]. Only those patients with a robust response to induction therapy by all three measures (clinical, radiographic, biochemical) are considered for an additional two months of systemic therapy. In the absence of a very robust response to chemotherapy alone, it is our practice to proceed directly to cXRT to minimize the risk of local disease progression after chemotherapy. Chemoradiation consists of a standard fractionation course of radiation (1.8 Gy/fx, M-F, 28 fractions) to a total dose of $50.4 \mathrm{~Gy}$. Gemcitabine is typically favored as the systemic agent, especially for those patients with arterial abutment in whom the most robust radiation effect is felt necessary. Restaging is completed four weeks after the last radiation treatment and, in the absence of disease progression or a change in clinical status, surgery is recommended.

The complexity of more prolonged neoadjuvant therapy using contemporary regimens, such as FOLFIRINOX in patients with borderline resectable disease, was recently published by our multidisciplinary working group [45]. Lessons learned from this early experience include: (1) durable biliary decompression (with a metal stent rather than polyethylene) is needed for those patients with an obstructed bile duct if neoadjuvant therapy is planned for more than 2 months; (2) careful attention to nutritional support and diabetes management is critical and; (3) there may be some patients of advanced age or significant medical co-morbidities who will not tolerate such extensive therapy, and in such patients the tumor may occasionally be operable but the patient is not a suitable operative candidate. This latter situation should not be viewed as a failure of treatment strategy. Such individuals likely received a superior clinical benefit from systemic therapy and cXRT than would have been realized from an upfront surgery, resulting in a grossly positive margin of resection.

\section{Conclusion}

Neoadjuvant treatment sequencing for patients with resectable or borderline resectable pancreatic cancer offers several established and theoretical benefits which are not realized with a surgery-first approach (Table 3). Among single institution studies, neoadjuvant therapy for pancreatic cancer has been associated with increased rates of margin negative resection, decreased perioperative morbidity, andincreased overall survival for those patients who completed all therapy [6] [32] [57]. Challenges exist in standardizing definitions of resectability and in implementing objective measures to improve the quality of radiographic, surgical, and pathologic assessments. Further study of novel agents, identification of predictive biomarkers of chemotherapeutic sensitivity, and the early detection of treatment response will add to the effectiveness of neoadjuvant therapy. For patients who demonstrate aggressive disease biology, neoadjuvant treatment sequencingwillsparethese individuals from an operation which in the setting of systemic diseasehas little benefit. Considering that surgery has a modest impact on the natural history of pancreatic cancer in most patients, a neoadjuvant approach to treatment sequencing is gaining support from clinicians of all specialties and will be the foundation for futurestudies of multimodality therapyin localized pancreatic cancer.

\section{Acknowledgements}

The authors acknowledge the support of the We Care Fund for Medical Innovation and Research, the Ronald Burklund Eich Pancreatic Research Fund, and the Lockton Funds for Pancreatic Cancer Research from the Department of Surgery at the Medical College of Wisconsin. ST acknowledges support from the Institutional Research Grant \# 86-004-26 from the American Cancer Society. The authors would like to thank Wendy Behrs for assistance with manuscript preparation. 


\section{References}

[1] Howlander, N.N.A., Krapcho, M., Garshell, J/, Miller, D., Altekruse, S.F., Kosary, C.L., Yu, M., Ruhl, J., Tatlovich, Z., Mariotto, A., Lewis, D.R., Chen, H.S., Feuer, E.J. and Cronin, K.A. (2015) SEER Cancer Statistics Review. 1975-2012. http://seer.cancer.gov/csr/1975_2012/

[2] Sohal, D.P., Walsh, R.M., Ramanathan, R.K. and Khorana, A.A. (2014) Pancreatic Adenocarcinoma: Treating a Systemic Disease with Systemic Therapy. Journal of the National Cancer Institute, 10, dju011. http://dx.doi.org/10.1093/jnci/dju011

[3] Casadei, R., Di Marco, M., Ricci, C., et al. (2015) Neoadjuvant Chemoradiotherapy and Surgery versus Surgery Alone in Resectable Pancreatic Cancer: A Single-Center Prospective, Randomized, Controlled Trial Which Failed to Achieve Accrual Targets. Journal of Gastrointestinal Surgery: Official Journal of the Society for Surgery of the Alimentary Tract; 19, 1802-1812. http://dx.doi.org/10.1007/s11605-015-2890-4

[4] Golcher, H., Brunner, T.B., Witzigmann, H., et al. (2015) Neoadjuvant Chemoradiation Therapy with Gemcitabine/ Cisplatin and Surgery versus Immediate Surgery in Resectable Pancreatic Cancer: Results of the First Prospective Randomized Phase II Trial. Strahlentherapie und Onkologie: Organ der Deutschen Rontgengesellschaft, 191, 7-16. http://dx.doi.org/10.1007/s00066-014-0737-7

[5] Evans, D.B., Rich, T.A., Byrd, D.R., et al. (1992) Preoperative Chemoradiation and Pancreaticoduodenectomy for Adenocarcinoma of the Pancreas. Archives of Surgery, 127, 1335-1339. http://dx.doi.org/10.1001/archsurg.1992.01420110083017

[6] Christians, K., Heimler, J.W., George, B., Ritch, P.S., Erickson, B.A., Johnston, F.M., Tolat, P.P., Foley, W.D., Evans, D.B. and Tsai, S. (2015) Survival of Patients with Resectable Pancreatic Cancer Receiving Neoadjuvant Therapy. 72nd Annual Meeting of the Central Surgical Society, 5-7 March 2015, Chicago. http://dx.doi.org/10.1016/j.surg.2015.09.018

[7] Winter, J.M., Brennan, M.F., Tang, L.H., et al. (2012) Survival after Resection of Pancreatic Adenocarcinoma: Results from a Single Institution over Three Decades. Annals of Surgical Oncology, 19, 169-175. http://dx.doi.org/10.1245/s10434-011-1900-3

[8] Appel, B.L., Tolat, P., Evans, D.B. and Tsai, S. (2012) Current Staging Systems for Pancreatic Cancer. Cancer Journal, 18, 539-549. http://dx.doi.org/10.1097/PPO.0b013e318278c5b5

[9] Smeenk, H.G., van Eijck, C.H., Hop, W.C., et al. (2007) Long-Term Survival and Metastatic Pattern of Pancreatic and Periampullary Cancer after Adjuvant Chemoradiation or Observation: Long-Term Results of EORTC Trial 40891. Annals of Surgery, 246, 734-740. http://dx.doi.org/10.1097/SLA.0b013e318156eef3

[10] Tepper, J., Nardi, G. and Sutt, H. (1976) Carcinoma of the Pancreas: Review of MGH Experience from 1963 to 1973. Analysis of Surgical Failure and Implications for Radiation Therapy. Cancer, 37, 1519-1524. http://dx.doi.org/10.1002/1097-0142(197603)37:3<1519::AID-CNCR2820370340>3.0.CO;2-O

[11] Van den Broeck, A., Sergeant, G., Ectors, N., Van Steenbergen, W., Aerts, R. and Topal, B. (2009) Patterns of Recurrence after Curative Resection of Pancreatic Ductal Adenocarcinoma. European Journal of Surgical Oncology, 35, 600-604. http://dx.doi.org/10.1016/j.ejso.2008.12.006

[12] Westerdahl, J., Andren-Sandberg, A. and Ihse, I. (1993) Recurrence of Exocrine Pancreatic Cancer-Local or Hepatic? Hepatogastroenterology, 40, 384-387.

[13] Kalser, M.H. and Ellenberg, S.S. (1985) Pancreatic Cancer. Adjuvant Combined Radiation and Chemotherapy Following Curative Resection. Archives of Surgery, 120, 899-903. http://dx.doi.org/10.1001/archsurg.1985.01390320023003

[14] Klinkenbijl, J.H., Jeekel, J., Sahmoud, T., van Pel, R., Couvreur, M.L., Veenhof, C.H., et al. (1999) Adjuvant Radiotherapy and 5-Fluorouracil after Curative Resection of Cancer of the Pancreas and Periampullary Region: Phase III Trial of the EORTC Gastrointestinal Tract Cancer Cooperative Group. Annals of Surgery, 230, 776-782. http://dx.doi.org/10.1097/00000658-199912000-00006

[15] Neoptolemos, J.P., Stocken, D.D., Friess, H., Bassi, C., Dunn, J.A., Hickey, H., et al. (2004) A Randomized Trial of Chemoradiotherapy and Chemotherapy after Resection of Pancreatic Cancer. The New England Journal of Medicine, 350, 1200-1210. http://dx.doi.org/10.1056/NEJMoa032295

[16] Oettle, H., Post, S., Neuhaus, P., Gellert, K., Langrehr, J., Ridwelski, K., et al. (2007) Adjuvant Chemotherapy with Gemcitabine vs Observation in Patients Undergoing Curative-Intent Resection of Pancreatic Cancer: A Randomized Controlled Trial. JAMA, 297, 267-277. http://dx.doi.org/10.1001/jama.297.3.267

[17] Neoptolemos, J.P., Stocken, D.D., Bassi, C., Ghaneh, P., Cunningham, D., Goldstein, D., et al. (2010) Adjuvant Chemotherapy with Fluorouracil plus Folinic Acid vs Gemcitabine Following Pancreatic Cancer Resection: A Randomized Controlled Trial. JAMA, 304, 1073-1081. http://dx.doi.org/10.1001/jama.2010.1275

[18] Valle, J.W., Palmer, D., Jackson, R., Cox, T., Neoptolemos, J.P., Ghaneh, P., et al. (2014) Optimal Duration and Tim- 
ing of Adjuvant Chemotherapy after Definitive Surgery for Ductal Adenocarcinoma of the Pancreas: Ongoing Lessons from the ESPAC-3 Study. Journal of Clinical Oncology, 32, 504-512. http://dx.doi.org/10.1200/jco.2013.50.7657

[19] Regine, W.F., Winter, K.W., Abrams, R., Safran, H., Hoffman, J.P., Konski, A., Benson, A.B., MacDonald, J.S., Willett, C.G. and Rich, T.A. (2006) RTOG 9704 a Phase III Study of Adjuvant Pre and Post Chemoradiation (CRT) 5-FU vs. Gemcitabine (G) for Resected Pancreatic Adenocarcinoma. Journal of Clinical Oncology, 24, 4007.

[20] Regine, W.F., Winter, K.A., Abrams, R., Safran, H., Hoffman, J.P., Konski, A., et al. (2011) Fluorouracil-Based Chemoradiation with either Gemcitabine or Fluorouracil Chemotherapy after Resection of Pancreatic Adenocarcinoma: 5-Year Analysis of the U.S. Intergroup/RTOG 9704 Phase III Trial. Annals of Surgical Oncology, 18, 1319-1326. http://dx.doi.org/10.1245/s10434-011-1630-6

[21] Abrams, R.A., Lowy, A.M., O’Reilly, E.M., Wolff, R.A., Picozzi, V.J. and Pisters, P.W. (2009) Combined Modality Treatment of Resectable and Borderline Resectable Pancreas Cancer: Expert Consensus Statement. Annals of Surgical Oncology, 16, 1751-1756. http://dx.doi.org/10.1245/s10434-009-0413-9

[22] National Comprehensive Cancer Network (2011) NCCN Practice Guidelines: Pancreatic Adenocarcinoma.

[23] Evans, D.B. and Wolff, R.A. (2011) Adjuvant Therapy for Pancreatic Cancer: A Logical Strategy in Search of Progress. Annals of Surgical Oncology, 18, 1224-1228. http://dx.doi.org/10.1245/s10434-011-1633-3

[24] Tempero, M.A., Arnoletti, J.P., Behrman, S., et al. (2010) Pancreatic Adenocarcinoma. Journal of the National Comprehensive Cancer Network, 8, 972-1017.

[25] Wu, W., He, J., Cameron, J.L., Makary, M., Soares, K., Ahuja, N., et al. (2014) The Impact of Postoperative Complications on the Administration of Adjuvant Therapy Following Pancreaticoduodenectomy for Adenocarcinoma. Annals of Surgical Oncology, 21, 2873-2881. http://dx.doi.org/10.1245/s10434-014-3722-6

[26] Pilepich, M.V. and Miller, H.H. (1980) Preoperative Irradiation in Carcinoma of the Pancreas. Cancer, 46, $1945-1949$. http://dx.doi.org/10.1002/1097-0142(19801101)46:9<1945::AID-CNCR2820460908>3.0.CO;2-X

[27] Takahashi, H., Ogawa, H., Ohigashi, H., Gotoh, K., Yamada, T., Ohue, M., et al. (2011) Preoperative Chemoradiation Reduces the Risk of Pancreatic Fistula after Distal Pancreatectomy for Pancreatic Adenocarcinoma. Surgery, 150, 547556. http://dx.doi.org/10.1016/j.surg.2011.03.001

[28] Raut, C.P., Evans, D.B., Crane, C.H., Pisters, P.W. and Wolff, R.A. (2004) Neoadjuvant Therapy for Resectable Pancreatic Cancer. Surgical Oncology Clinics of North America, 13, 639-661. http://dx.doi.org/10.1016/j.soc.2004.06.007

[29] Willett, C.G., Lewandrowski, K., Warshaw, A.L., Efird, J. and Compton, C.C. (1993) Resection Margins in Carcinoma of the Head of the Pancreas. Implications for Radiation Therapy. Annals of Surgery, 217, 144-148. http://dx.doi.org/10.1097/00000658-199302000-00008

[30] Pisters, P.W., Hudec, W.A., Lee, J.E., et al. (2000) Preoperative Chemoradiation for Patients with Pancreatic Cancer: Toxicity of Endobiliary Stents. Journal of Clinical Oncology, 18, 860-867.

[31] Aadam, A.A., Evans, D.B., Khan, A., Oh, Y. and Dua, K. (2012) Efficacy and Safety of Self-Expandable Metal Stents for Biliary Decompression in Patients Receiving Neoadjuvant Therapy for Pancreatic Cancer: A Prospective Study. Gastrointestinal Endoscopy, 76, 67-75. http://dx.doi.org/10.1016/j.gie.2012.02.041

[32] Varadhachary, G.R., Wolff, R.A., Crane, C.H., Sun, C.C., Lee, J.E., Pisters, P.W.T., et al. (2008) Preoperative Gemcitabine and Cisplatin Followed by Gemcitabine-Based Chemoradiation for Resectable Adenocarcinoma of the Pancreatic Head. Journal of Clinical Oncology, 26, 3487-3495. http://dx.doi.org/10.1200/jco.2007.15.8642

[33] Talamonti, M.S., Small Jr., W., Mulcahy, M.F., Wayne, J.D., Attaluri, V., Colletti, L.M., et al. (2006) A Multi-Institutional Phase II Trial of Preoperative Full-Dose Gemcitabine and Concurrent Radiation for Patients with Potentially Resectable Pancreatic Carcinoma. Annals of Surgical Oncology, 13, 150-158. http://dx.doi.org/10.1245/ASO.2006.03.039

[34] Tzeng, C.W., Tran Cao, H.S., Lee, J.E., et al. (2014) Treatment Sequencing for Resectable Pancreatic Cancer: Influence of Early Metastases and Surgical Complications on Multimodality Therapy Completion and Survival. Journal of Gastrointestinal Surgery, 18, 16-24.

[35] Kim, E.J., Ben-Josef, E., Herman, J.M., Bekaii-Saab, T., Dawson, L.A., Griffith, K.A., et al. (2013) A Multi-Institutional Phase 2 Study of Neoadjuvant Gemcitabine and Oxaliplatin with Radiation Therapy in Patients with Pancreatic Cancer. Cancer, 119, 2692-2700. http://dx.doi.org/10.1002/cncr.28117

[36] O’Reilly, E.M., Perelshteyn, A., Jarnagin, W.R., Schattner, M., Gerdes, H., Capanu, M., et al. (2014) A Single-Arm, Nonrandomized Phase II Trial of Neoadjuvant Gemcitabine and Oxaliplatin in Patients with Resectable Pancreas Adenocarcinoma. Annals of Surgery, 260, 142-148. http://dx.doi.org/10.1097/SLA.0000000000000251

[37] Rose, J.B., Rocha, F.G., Alseidi, A., Biehl, T., Moonka, R., Ryan, J.A., Lin, B., Picozzi, V. and Helton, S. (2014) Extended Neoadjuvant Chemotherapy for Borderline Resectable Pancreatic Cancer Demonstrates Promising Postoperative Outcomes and Survival. Annals of Surgical Oncology, 21, 1530-1537.

http://dx.doi.org/10.1245/s10434-014-3486-z 
[38] Ferrone, C.R., Marchegiani, G., Hong, T.S., Ryan, D.P., Deshpande, V., McDonnell, E.I., et al. (2015) Radiological and Surgical Implications of Neoadjuvant Treatment with FOLFIRINOX for Locally Advanced and Borderline Resectable Pancreatic Cancer. Annals of Surgery, 261, 12-17. http://dx.doi.org/10.1097/SLA.0000000000000867

[39] Evans, D.B., Varadhachary, G.R., Crane, C.H., Sun, C.C., Lee, J.E., Pisters, P.W.T., et al. (2008) Preoperative Gemcitabine-Based Chemoradiation for Patients with Resectable Adenocarcinoma of the Pancreatic Head. Journal of Clinical Oncology, 26, 3496-3502. http://dx.doi.org/10.1200/JCO.2007.15.8634

[40] Christians, K., Heimler, J.W., George, B., Ritch, P.S., Erickson, B.A., Johnston, F.M., Tolat, P.P., Foley, W.D., Evans, D.B. and Tsai, S. Survival of Patients with Resectable Pancreatic Cancer Receiving Neoadjuvant Therapy. Surgery 2015.

[41] Shibuya, K.C., Goel, V.K., Xiong, W., Sham, J.G., Pollack, S.M., Leahy, A.M., et al. (2014) Pancreatic Ductal Adenocarcinoma Contains an Effector and Regulatory Immune Cell Infiltrate That Is Altered by Multimodal Neoadjuvant Treatment. PLoS ONE, 9, e96565. http://dx.doi.org/10.1371/journal.pone.0096565

[42] Conroy, T., Desseigne, F., Ychou, M., Bouché, O., Guimbaud, R., Bécouarn, Y., et al. (2011) FOLFIRINOX versus Gemcitabine for Metastatic Pancreatic Cancer. The New England Journal of Medicine, 364, 1817-1825. http://dx.doi.org/10.1056/NEJMoa1011923

[43] Von Hoff, D.D., Goldstein, D. and Renschler, M.F. (2014) Albumin-Bound Paclitaxel plus Gemcitabine in Pancreatic Cancer. The New England Journal of Medicine, 370, 479-480.

[44] Mahaseth, H., Brutcher, E., Kauh, J., Hawk, N., Kim, S., Chen, Z., et al. (2013) Modified FOLFIRINOX Regimen with Improved Safety and Maintained Efficacy in Pancreatic Adenocarcinoma. Pancreas, 42, 1311-1315. http://dx.doi.org/10.1097/MPA.0b013e31829e2006

[45] Christians, K.K., Tsai, S., Mahmoud, A., Ritch, P., Thomas, J.P., Wiebe, L., et al. (2014) Neoadjuvant FOLFIRINOX for Borderline Resectable Pancreas Cancer: A New Treatment Paradigm? The Oncologist, 19, 266-274. http://dx.doi.org/10.1634/theoncologist.2013-0273

[46] University of Pittsburgh (2015) Phase II Neoadjuvant Chemotheraphy (Gemcitabine and Nab-Paclitaxel vs. mFOLFIRINOX) and Sterotatic Body Radiation Therapy for Borderline Resectable Pancreatic Cancer. https://clinicaltrials.gov/ct2/show/NCT02241551?term=02241551\&rank=1

[47] Medical College of Wisconsin (2015) Pancreas Cancer: Molecular Profiling as a Guide to Therapy before and after Surgery. ClinicalTrials.gov [Internet], National Library of Medicine (US), Bethesda.

[48] Gillen, S., Schuster, T., Meyer Zum Buschenfelde, C., Friess, H. and Kleeff, J. (2010) Preoperative/Neoadjuvant Therapy in Pancreatic Cancer: A Systematic Review and Meta-Analysis of Response and Resection Percentages. PLoS Medicine, 7, e1000267. http://dx.doi.org/10.1371/journal.pmed.1000267

[49] Katz, M.H., Pisters, P.W., Evans, D.B., Sun, C.C., Lee, J.E., Fleming, J.B., et al. (2008) Borderline Resectable Pancreatic Cancer: The Importance of This Emerging Stage of Disease. Journal of the American College of Surgeons, 206, 833-846. http://dx.doi.org/10.1016/j.jamcollsurg.2007.12.020

[50] Patel, M., Hoffe, S., Malafa, M., Hodul, P., Klapman, J., Centeno, B., et al. (2011) Neoadjuvant GTX Chemotherapy and IMRT-Based Chemoradiation for Borderline Resectable Pancreatic Cancer. Journal of Surgical Oncology, 104, 155-161. http://dx.doi.org/10.1002/jso.21954

[51] McClaine, R.J., Lowy, A.M., Sussman, J.J., Schmulewitz, N., Grisell, D.L. and Ahmad, S.A. (2010) Neoadjuvant Therapy May Lead to Successful Surgical Resection and Improved Survival in Patients with Borderline Resectable Pancreatic Cancer. HPB, 12, 73-79. http://dx.doi.org/10.1111/j.1477-2574.2009.00136.x

[52] Stokes, J.B., Nolan, N.J., Stelow, E.B., Walters, D.M., Weiss, G.R., de Lange, E.E., Rich, T.A., Adams, R.B. and Bauer, T.W. (2011) Preoperative Capecitabine and Concurrent Radiation for Borderline Resectable Pancreatic Cancer. Annals of Surgical Oncology, 18, 619-627. http://dx.doi.org/10.1245/s10434-010-1456-7

[53] Fine, R.L., Fogelman, D.R., Schreibman, S.M., Desai, M., Sherman, W., Strauss, J., Guba, S., Andrade, R. and Chabot, J. (2008) The Gemcitabine, Docetaxel, and Capecitabine (GTX) Regimen for Metastatic Pancreatic Cancer: A Retrospective Analysis. Cancer Chemotherapy and Pharmacology, 61, 167-175. http://dx.doi.org/10.1007/s00280-007-0473-0

[54] Von Hoff, D.D., Ramanathan, R.K., Borad, M.J., Laheru, D.A., Smith, L.S., Wood, T.E., et al. (2011) Gemcitabine plus nab-Paclitaxel Is an Active Regimen in Patients with Advanced Pancreatic Cancer: A Phase I/II Trial. Journal of Clinical Oncology, 29, 4548-4554. http://dx.doi.org/10.1200/JCO.2011.36.5742

[55] Pilgrim, C.H., Tsai, S., Tolat, P., Patel, P., Rilling, W., Evans, D.B. and Christians, K.K. (2014) Optimal Management of the Splenic Vein at the Time of Venous Resection for Pancreatic Cancer: Importance of the Inferior Mesenteric Vein. Journal of Gastrointestinal Surgery, 18, 917-921. http://dx.doi.org/10.1007/s11605-013-2428-6

[56] Evans, D.B., George, B. and Tsai, S. (2015) Non-Metastatic Pancreatic Cancer: Resectable, Borderline Resectable, and Locally Advanced-Definitions of Increasing Importance for the Optimal Delivery of Multimodality Therapy. Annals of 
Surgical Oncology, 22, 3409-3413. http://dx.doi.org/10.1245/s10434-015-4649-2

[57] Katz, M.H., Wang, H., Fleming, J.B., Sun, C.C., Hwang, R.F., Wolff, R.A., et al. (2009) Long-Term Survival after Multidisciplinary Management of Resected Pancreatic Adenocarcinoma. Annals of Surgical Oncology, 16, 836-847. http://dx.doi.org/10.1245/s10434-008-0295-2

[58] Oettle, H., Neuhaus, P., Hochhaus, A., Hartmann, J.T., Gellert, K., Ridwelski, K., et al. (2013) Adjuvant Chemotherapy with Gemcitabine and Long-Term Outcomes among Patients with Resected Pancreatic Cancer: The CONKO-001 Randomized Trial. JAMA, 310, 1473-1481. http://dx.doi.org/10.1001/jama.2013.279201

[59] Yeung, R.S., Weese, J.L., Hoffman, J.P., Solin, L.J., Paul, A.R., Engstrom, P.F., Litwin, S., Kowalyshyn, M.J. and Eisenberg, B.L. (1993) Neoadjuvant Chemoradiation in Pancreatic and Duodenal Carcinoma. A Phase II Study. Cancer, 72, 2124-2133. http://dx.doi.org/10.1002/1097-0142(19931001)72:7<2124::AID-CNCR2820720711>3.0.CO;2-C

[60] Pisters, P.W., Abbruzzese, J.L., Janjan, N.A., et al. (1998) Rapid-Fractionation Preoperative Chemoradiation, Pancreaticoduodenectomy, and Intraoperative Radiation Therapy for Resectable Pancreatic Adenocarcinoma. Journal of Clinical Oncology, 16, 3843-3850.

[61] Hoffman, J.P., Lipsitz, S., Pisansky, T., Weese, J.L., Solin, L. and Benson III, A.B. (1998) Phase II Trial of Preoperative Radiation Therapy and Chemotherapy for Patients with Localized, Resectable Adenocarcinoma of the Pancreas: An Eastern Cooperative Oncology Group Study. Journal of Clinical Oncology, 16, 317-323.

[62] White, R.R., Hurwitz, H.I., Morse, M.A., Lee, C., Anscher, M.S., Paulson, E.K., et al. (2001) Neoadjuvant Chemoradiation for Localized Adenocarcinoma of the Pancreas. Annals of Surgical Oncology, 8, 758-765. http://dx.doi.org/10.1007/s10434-001-0758-1

[63] Pisters, P.W., Wolff, R.A., Janjan, N.A., Cleary, K.R., Charnsangavej, C., Crane, C.N., et al. (2002) Preoperative Paclitaxel and Concurrent Rapid-Fractionation Radiation for Resectable Pancreatic Adenocarcinoma: Toxicities, Histologic Response Rates, and Event-Free Outcome. Journal of Clinical Oncology, 20, 2537-2544. http://dx.doi.org/10.1200/JCO.2002.11.064

[64] Moutardier, V., Magnin, V., Turrini, O., Viret, F., Hennekinne-Mucci, S., Gonçalves, A., et al. (2004) Assessment of Pathologic Response after Preoperative Chemoradiotherapy and Surgery in Pancreatic Adenocarcinoma. International Journal of Radiation Oncology, Biology, Physics, 60, 437-443. http://dx.doi.org/10.1016/j.jjrobp.2004.04.004

[65] Mornex, F., Girard, N., Delpero, J.R. and Partensky, C. (2005) Radiochemotherapy in the Management of Pancreatic Cancer-Part I: Neoadjuvant Treatment. Seminars in Radiation Oncology, 15, 226-234. http://dx.doi.org/10.1016/j.semradonc.2005.04.008

[66] Turrini, O., Viret, F., Moureau-Zabotto, L., Guiramand, J., Moutardier, V., Lelong, B., et al. (2009) Neoadjuvant 5 Fluorouracil-Cisplatin Chemoradiation Effect on Survival in Patients with Resectable Pancreatic Head Adenocarcinoma: A Ten-Year Single Institution Experience. Oncology, 76, 413-419. http://dx.doi.org/10.1159/000215928

[67] Le Scodan, R., Mornex, F., Girard, N., Mercier, C., Valette, P.-J., Ychou, M., et al. (2009) Preoperative Chemoradiation in Potentially Resectable Pancreatic Adenocarcinoma: Feasibility, Treatment Effect Evaluation and Prognostic Factors, Analysis of the SFRO-FFCD 9704 Trial and Literature Review. Annals of Oncology, 20, 1387-1396. http://dx.doi.org/10.1093/annonc/mdp015

[68] Turrini, O., Ychou, M., Moureau-Zabotto, L., Rouanet, P., Giovannini, M., Moutardier, V., Azria, D., Delpero, J.-R. and Viret, F. (2010) Neoadjuvant Docetaxel-Based Chemoradiation for Resectable Adenocarcinoma of the Pancreas: New Neoadjuvant Regimen Was Safe and Provided an Interesting Pathologic Response. European Journal of Surgical Oncology, 36, 987-992. http://dx.doi.org/10.1016/j.ejso.2010.07.003

[69] Kang, C.M., Chung, Y.E., Park, J.Y., Sung, J.S., Hwang, H.K., Choi, H.J., Kim, H., Song, S.Y. and Lee, W.J. (2012) Potential Contribution of Preoperative Neoadjuvant Concurrent Chemoradiation Therapy on Margin-Negative Resection in Borderline Resectable Pancreatic Cancer. Journal of Gastrointestinal Surgery, 16, 509-517. http://dx.doi.org/10.1007/s11605-011-1784-3

[70] Artinyan, A., Anaya, D.A., McKenzie, S., Ellenhorn, J.D. and Kim, J. (2011) Neoadjuvant Therapy Is Associated with Improved Survival in Resectable Pancreatic Adenocarcinoma. Cancer, 117, 2044-2049. http://dx.doi.org/10.1002/cncr.25763

[71] Lee, J.L., Kim, S.C., Kim, J.H., Lee, S.S., Kim, T.-W., Park, D.H., et al. (2012) Prospective Efficacy and Safety Study of Neoadjuvant Gemcitabine with Capecitabine Combination Chemotherapy for Borderline-Resectable or Unresectable Locally Advanced Pancreatic Adenocarcinoma. Surgery, 152, 851-862. http://dx.doi.org/10.1016/j.surg.2012.03.010

[72] Sho, M., Akahori, T., Tanaka, T., Kinoshita, S., Tamamoto, T., Nomi, T., et al. (2013) Pathological and Clinical Impact of Neoadjuvant Chemoradiotherapy Using Full-Dose Gemcitabine and Concurrent Radiation for Resectable Pancreatic Cancer. Journal of Hepato-Biliary-Pancreatic Sciences, 20, 197-205. http://dx.doi.org/10.1007/s00534-012-0532-8

[73] Pipas, J.M., Zaki, B.I., McGowan, M.M., Tsapakos, M.J., Ripple, G.H., Suriawinata, A.A., et al. (2012) Neoadjuvant 
Cetuximab, Twice-Weekly Gemcitabine, and Intensity-Modulated Radiotherapy (IMRT) in Patients with Pancreatic Adenocarcinoma. Annals of Oncology, 23, 2820-2827. http://dx.doi.org/10.1093/annonc/mds109

[74] Arvold, N.D., Ryan, D.P., Niemierko, A., Blaszkowsky, L.S., Kwak, E.L., Wo, J.Y., et al. (2012) Long-Term Outcomes of Neoadjuvant Chemotherapy before Chemoradiation for Locally Advanced Pancreatic Cancer. Cancer, 118, 3026-3035. http://dx.doi.org/10.1002/cncr.26633

[75] Barugola, G., Partelli, S., Crippa, S., Capelli, P., D’Onofrio, M., Pederzoli, P. and Falconi, M. (2012) Outcomes after Resection of Locally Advanced or Borderline Resectable Pancreatic Cancer after Neoadjuvant Therapy. American Journal of Surgery, 203, 132-139. http://dx.doi.org/10.1016/j.amjsurg.2011.03.008

[76] Leone, F., Gatti, M., Massucco, P., Colombi, F., Sperti, E., Campanella, D., et al. (2013) Induction Gemcitabine and Oxaliplatin Therapy Followed by a Twice-Weekly Infusion of Gemcitabine and Concurrent External-Beam Radiation for Neoadjuvant Treatment of Locally Advanced Pancreatic Cancer: A Single Institutional Experience. Cancer, 119, 277-284. http://dx.doi.org/10.1002/cncr.27736

[77] Van Buren II, G., Ramanathan, R.K., Krasinskas, A.M., Smith, R.P., Abood, G.J., Bahary, N., et al. (2013) Phase II Study of Induction Fixed-Dose Rate Gemcitabine and Bevacizumab Followed by 30 Gy Radiotherapy as Preoperative Treatment for Potentially Resectable Pancreatic Adenocarcinoma. Annals of Surgical Oncology, 20, 3787-3793. http://dx.doi.org/10.1245/s10434-013-3161-9

[78] Motoi, F., Ishida, K., Fujishima, F., Ottomo, S., Oikawa, M., Okada, T., et al. (2013) Neoadjuvant Chemotherapy with Gemcitabine and S-1 for Resectable and Borderline Pancreatic Ductal Adenocarcinoma: Results from a Prospective Multi-Institutional Phase 2 Trial. Annals of Surgical Oncology, 20, 3794-3801. http://dx.doi.org/10.1245/s10434-013-3129-9

[79] Cho, I.R., Chung, M.J., Bang, S., Park, S.W., Chung, J.B., Song, S.Y., et al. (2013) Gemcitabine Based Neoadjuvant Chemoradiotherapy Therapy in Patients with Borderline Resectable Pancreatic Cancer. Pancreatology, 13, 539-543. http://dx.doi.org/10.1016/j.pan.2013.07.064

[80] Epelboym, I., DiNorcia, J., Winner, M., Lee, M.K., Lee, J.A., Schrope, B.A., Chabot, J.A. and Allendorf, J.D. (2014) Neoadjuvant Therapy and Vascular Resection during Pancreaticoduodenectomy: Shifting the Survival Curve for Patients with Locally Advanced Pancreatic Cancer. World Journal of Surgery, 38, 1184-1195. http://dx.doi.org/10.1007/s00268-013-2384-z

[81] Blazer, M., Wu, C., Goldberg, R.M., Phillips, G., Schmidt, C., Muscarella, P., et al. (2014) Neoadjuvant Modified (m) FOLFIRINOX for Locally Advanced Unresectable (LAPC) and Borderline Resectable (BRPC) Adenocarcinoma of the Pancreas. Annals of Surgical Oncology, 22, 1153-1159.

[82] Katz, M., Shi, Q., Ahmad, S.A., Herman, J.M., Marsh, R., Collisson, E.A., Schwartz, L.H., Martin, R.C.G., Conway, W.C., Truty, M., Kindler, H.L., Lowy, A.M., Philip, P.A., Bekaii-Saab, T.S., Cardin, D.B., LoConte, N.K. and Venook, A.P. (2015) Preoperative Modified FOLFIRINOX (mFOLFIRINOX) Followed by Chemoradiation (CRT) for Borderline Resectable (BLR) Pancreatic Cancer (PC): Initial Results from Alliance Trial A021101. Journal of Clinical Oncology, 33, Abstract No. 4008. 